\title{
Application of Sodium Alginate Hydrogel
}

\author{
Wael jumah Aljohani ${ }^{1,2,3}$, li wenchao ${ }^{3}$,Muhammad Wajid Ullah ${ }^{1,2,}$, \\ Xianglin Zhang ${ }^{3}$, Guang Yang ${ }^{1,2}$, \\ ${ }^{I}$ Department of Biomedical Engineering, Huazhong University of Science and Technology, Wuhan 430074, P.R \\ China \\ ${ }^{2}$ National Engineering Research Center for Nano-Medicine, Huazhong University of Science and Technology, \\ Wuhan 430074, PR China \\ ${ }^{3}$ School of Materials Science and Engineering, Huazhong University of Science and Technology, Wuhan \\ 430074, P.R China
}

\begin{abstract}
Tissue engineering and 3D cell cutler involving the use of three-dimensional scahffold for cell and tissue cultural, is a promising technique for establishing in vitro culture models that mimc in vivo environment . In vitro models present ethical and cost advantages over in vivo models, and allow for tissue devolpmint.alginate, aliner polysaccharide derived from brown algae .has properties that make it a favorable materials as a 3D extracellular matrix for in vitro cell and tissue models and some of sodium Hydrogyl materials are higly appealing as $3 D$ scaffold for in vitro $3 D$ cell cutlre and tissue culture due their ability to mimic the physical properties native tissue as well as their high porosity for effcient diffusion of proteins and nutrients Alginate hydrogel is widely ysed in tissue engineering application due to its desirable propertis as Biomaterials.
\end{abstract}

\section{Introduction}

Within the Early 1940s, both cells and tissues have been considered to be intellectual, most probably highly related to glass and several kinds of surfaces, Nowadays, it is highly required for various materials to be easily controlled as well as printed culture systems that are responsible for upholding cells more materials controllable and printing culture systems that upholding cells enhancement and having the criteria of being extravagant, and discriminative establishment as found in tissues [1] it has been known that several formats and materials have been represented for three-dimensional culture of the cell and tissue engineering. glycosamino-glycans that are gelatinous and over going through the process of hydration, glycoproteins in addition to proteo-glycans [2] . This paper will deal with the physical maneuvers of the hydrogel formats variable shapes such as, retardation, gels that can easily molded and injected in addition to the micro-porous structural profile. Hydrogel is a polymeric material that exhibit- its ability of retention of a reasonable significant amount of water including its entire structure, and it has no ability to be dissolved in water it also have an optimum level of flexibility as their natural tissues because of their hydrogel water constituents competence that can absorb the water-arise correlated with its hydrophilic functional groups connected to the backbone of the polymer, and there are a variety of materials that can be occurred and synthetized normally and show a high significance with hydrogel description.[3] Furthermore, it shows the ability of being stable in both the strong as well as the sharp c.f and strong temperatures fluctuations. hydrogel we use for Biomaterials prepared to be inert in correlation to the steward system of biology . because, it has been revealed that most of the naturally driven materials show significances with biomaterials can be used to replace the tissues that have been lost due to shock. in the period of 2000s, artificial polymers have started to replace biomaterials, because their better execution, and more reproducible, [3,4]. The more recent germination is leading to the biomaterial introduction of being interfaced within biological systems for the ease of evaluation, treatment in addition to the mission of the body [5], and has been extensively inspected, and used for many Application biomedical because he relatively low cost and due to its biocompatibility Alginate hydrogels can be prepared in several methods, it can also be used for providing a broad number of living tissues applications in incision curing, presentation of the bioactive agents as wound sited and minimize bacterial infection [5] It has been conducted in several animal researches with a relatively small clinical trials scale, they have the ability to be highly tolerable, Moreover, they show a proper correspondence with both steward and withringed cells; sterile filtering way of sterilization can be utilized for their fineness confirmation. [6] Alginate hydrogels also can provide a wide application of biomolecules matrices, and play a reasonable role in pharmaceutical materials preparation of the locally administrative substances [7] Alginate is available in both the charged form as well as the neutral one therefore, it is considered to be appropriate with numerous substances . 


\subsection{Alginate Structure and Chemistry}

\section{Different Methodology Of Sodium Alginate Hydrogel}

One of the general properties of Alginate is being a highly natural revolving polymer similar to the extracted brown seaweed In general and As biomaterials, alginates can into a variety of soft, gels, nanoparticles, multilayers etc. at physiological conditions ensuring the conservation of cell viability and function. fermentation of bacteria . alginate is also considered as a pace poly-saccharide co-polymer containg (14)-linked $\beta$-D-mannuronic acid ( $\mathrm{M}$ units) in addition to $\alpha$-L-guluronic acid ( $\mathrm{G}$ units) (fighure 1 )monomers. in the alginate polymer, Both $\mathrm{M}$ and $\mathrm{G}$ units shows a relatively frequent assembly in both duplicating -M-M- / -GG- as well corresponding M-G blocks. some of the obvious criteria of alginate as well as its hydrogel show edema, transmittance, in addition to the ability of being viscoelastic, are highly impacted by the M and $\mathrm{G}$ units rational calculations [7] Normally most of the algal alginates G components ranges from $30 \%$ to $70 \%$ percent. Their blocks differs in both the distribution as well as the length regarding species in addition the extracted portion of the alginate from seaweed.

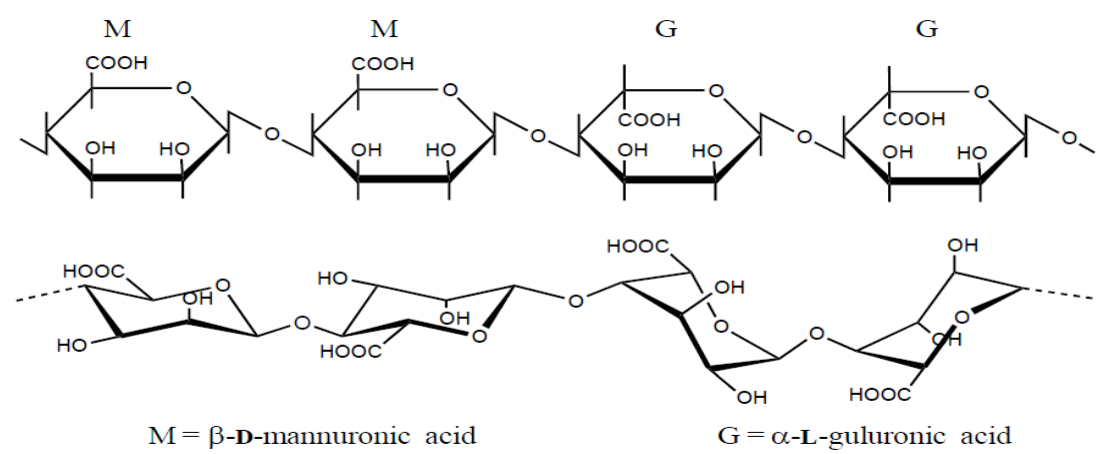

Figure 1. The structure of alginate shown as the segment of ..MMGG.. residues [18]. Epimerisation of the M residues changes the conformation of the sugar from $4 \mathrm{C} 1$ to $1 \mathrm{C} 4[19,20]$

\subsection{Methodology of sodium alginate Hydrogel}

Matter for methods have been growing progressively and convey to perform the hydrogels of the alginate among different applications of biomaterial engineering. Extreme number of ways of are depending on the internal and diffusive gelling that outgo the process of foundation. Regarding the initiative organization, ca-cl solution is pressed within the alginate barrage and the process of gelation is then begun starts in two successive reagents gelation proceeding into the solution of the alginate as calcium ions prevalent to the body of the alginate. However, it is difficult to be controlled over scaffold [8]

The second way is manipulated by overturning of both the calcium chloride solutions and the alginate upwards and backwards in a double- nozzle process attached via a triad method of stopcock till reaching the aimed supple hydrogel[9] The major strong point of this technique is the ease of a constantly gel like achievement .Amongst the reason of having mechanical obligation the mentioned organizations can be used as ways to brew sodium alginate hydrogel scaffolds. A way of them is carried out by mixing the alginate and the calcium ions with the usage of a mechanical require such as mixing of the aquatic alginate together with the solution of calcium gluconate solution by the manipulation of homogenization for the means of dispensing the calcium ions with the prepared solutions to make the process of alginate hydrogel injection performed easily [10] In another technique, the alginate solution in the same way can be put to the divalent ions barrage a(calcium chloride solution as an example) followed by the gelation process procedure that begins within the exterior alginate surface that enhances the process of the calcium ions diffusion to the material core. Via alginate manipulation in several techniques of fabrication, this way conducts the ability to carry out tissue scaffolds via the architecture complex. Even though, the existence of valuable amount of calcium ions concentration is considered to be a critical target for both the of living cells in addition to the biomolecules for the means of the process of bio-fabrication. This paper concentrates on way this technique can interact with the process and how far it could affect the viability of the cells in the time of fabrication and even after it. [9][10]

\subsection{Chemical modifications}

Alginate Hydrogyl free hydroxyl carboxyl groups along its molecule series stretch considerable sites that are quixotic for chemical functionalization. possession such as hydrophobicity degradability, and biological property can be altered by functionalizing available hydroxyl or carboxyl groups, or meddlesome with carboncarbon bonds [11]. For example, to decrease alginate gel stiffness and accretion degradability inc physiological onditions, oxidation of alginate is often employed, which lowers the molecular weight (MW) of the 
polysaccharide Sodium periodate, which is used for the oxidation reactions, breaks carbon-carbon bonds of the guluronate group yielding an adduct that does not form ionic bridges with divalent cations [12]; therefore, less crosslinking occurs, leading to lower mechanical stiffness of the resulting gel. Furthermore, partial oxidation of alginate creates acetal groups that are susceptible to hydrolysis. Consequently, increasing the degree of oxidation increases degradability of the resulting alginate gel in physiological conditions [13]. Another useful way of alginate chemical modification is to go within the process of sulfating that can be prepared by formamide chlorosulfuric acid interaction with alginate [14]. This process delivers a structural like heparin(Alginate) and thus promotes an efficient compatibility of the blood. Sulfating process of the alginate also mimics heparin's high affinity for certain factors related to growth ; therefore, the sulfated alginate hydrogels can be utilized for providing both a protected and sustained heparin interacting growth factors release, Basic fibroblast growth factor(as an example), which plays an important role in the delivery systems of vivo in addition to the applications of the tissue engineering. [15].

A common alginate modification for the purpose of the encapsulation of cells, is known as amidation, that carbodiimides the chemistry used to form amide linkages with the molecules containing amines and the functional groups of the polymer backbone of the alginate carboxylic acid [16]. This type of chemistry has been used for covalently linkage peptides to the backbone of the alginate to enhance the matrix of the cell interactions, adhesion of the cells is considered to be a major requirement regarding both the proliferation as well as the validity of the cells [17]. The aspartic acid of the arginine-glycine- (RGD) peptide chain, that is available in the matrix of the extracellular proteins as an example laminin and fibro-nectin, is the highly valuable and most commonly performed peptide chain to carry out the adhesion process[18]. Thus highly attached to the alginate, RGD peptide locations can word as suppliers to the integrins of the cell in order to handle the process of adhesion and migration, and the ligand density differs in order to get reasonable adhesion level [19]. Overall, all the chemical and physical chemical characteristics of alginate go to come to the fact that leads it to be an ideal candidate as a 3-D matrix for tissue engineering strategies, including those used for the establishment of the functional and the developmental tissues in vitro.

\subsection{In vitro models of development}

While traditional tissue engineering studies have focused on using scaffolds for tissue regeneration for transplantation therapies, as described earlier, the field of tissue engineering, in particular the use of scaffolds, is now being explored for other applications, such as studies on drug efficacy and toxicology as well as investigations on tissue development and morphogenesis. For these applications, an in vitro tissue model presents many strong feedback in cost and ethics ethical and throughout the models of vivo, enhancing further mechanistic researches for simple, controlled systems [20]. Traditional two-dimensional (2-D) culture systems reveals to a direct attachment of the cells within the substrate(which is known as cell-to-cell interactions) followed by migration from the tissues [21,22]. Consequently, cells and tissue often behave very differently when cultured in two dimensions and experience major differences in gene expression due to the lack of a natural 3-D environment [23]. Three-dimensional culture systems have the ability of embryo maintenance and the architecture of tissues enhancing a straight forward physical interaction within the involving environment, that sufficiently correspondent in the development of vivo.

11 Thus, the tissue engineering approach provides an exciting, more physiologically natural alternative to traditional 2-D systems as in vitro models of development. The use of tissue engineering principles to establish in vitro models that closely resemble in vivo conditions provides a means for researchers to evaluate normal and abnormal embryo or tissue development, as well as factors that affect development. Understanding native embryo and tissue development is important for advancing the field of developmental biology, which focuses on uncovering mechanisms involved in cell growth, differentiation, and morphogenesis. Knowledge of developmental biology mechanisms, specifically those involving gene regulation of cell differentiation and tissue specification, can be integrated with other biological fields to help solve major questions that still exist in those areas [24].Examples of in vitro culture systems that have employed the tissue engineering approach include models for ovarian follicle [25-26] and embryo development [26-27], as well as in vitro organ models such as kidney [31], cardiac [52], skin [53], and oviduct models [28]. Human skin models, in particular, have served as in vitro test systems for pharmaceutical research [29], and cardiac tissue models have provided a means for electrophysiological studies of the heart [30], a complicated task to evaluate by in vivo measures. In addition, in vitro tumor models have recently become highly appealing for studying the efficiency of chemotherapy drugs [31], as well as factors involved in tumor initiation and progression [32]. The physiological and pathophysiological knowledge that have been obtained from by the usage of these models in vitro can be a research methodology for improving the fertilization rate in addition to the outcomes of the pregnancy and both tissue engineering and cell-based treatment therapies for the degenerative diseases. The research presented in this thesis specifically focuses on the establishment of two separate in vitro models of development using alginate hydrogel as the 3-D matrix: a model for the development of pre- implantation pig embryos and an in 
vitro growth plate model. The context and impact of these two culture models are presented in the following sections.

\section{Applications}

Alginate is he can used in the food industry as a intensification, the different quality of foods, such as dressings, establish its biocompatibility and not toxicity [33]. The gels of alginate can be also manipulated to enhance liberation macromolecules in a controlled pattern and can be orally manage and injected in a noninvasive accession [34]. Recently, alginate research has relocate to tissue engineering applications due to its relocate, relatively low cost, and superfine gelation process [33, 35]. alginate hydrogels are its very appropriate for cell transplantation and can simply present cells to the site of interest in vivo or supply and a controlled 3-D environment for new tissue formation in vitro [35]. The gels of alginate can also be manifested for the culture of numerous cell types, including articular chondrocytes [35, 36], skeletal myoblasts [36, 37], neural stem cells [28], and mouse embryonic stem cells [38]. The tissue engineering approach to cell and tissue culture, including the usage of the three-dimensional (3-D) scaffolds, is considered to be an optimum way for achievement in the culture models of vitro which correlates with the vivo environments. Alginate, is known as a polysaccharide of a linear origin that has been extracted from brownish algae, showing several characteristics that leads it to be a material preferable to be used for the matrix of extracellular 3-D matrix for both the models of the tissues and the vitro cells in vitro cell making an intimate cross-linkage of the hydrogels and ions in the existence of a divalent cation, obtaining a profound encapsulation of tissues and cells. In addition, alginate hydrogel can go through chemical modification conducting a specific interactions within the cells or tissues that surround the hydrogel, or can be left unmodified to solely provide mechanical support for tissue morphogenesis and/or cellular responses. For this thesis, alginate hydrogel was used to develop a double system of cultural separation that interacts as a targeted maneuver in serving the functional and developmental vitro models. For the first project, alginate hydrogel was investigated as a 3-D matrix for the in vitro development of preimplantation pig embryos. Within the range of the tenth and the twelve day of pig gestation, embryos go to a complicated procedure of morphological changes, that is described in terms of elongation. Deficiencies concerning the elongation process lead to a more than 20 percent of embryonic loss, however the real elongation mechanisms are still controversial. In order to provide a proper key method of vitro evaluating mechanisms regarding elongation, the first objective of this thesis is to manipulate the hydrogels of the alginate as 3-D scaffolds for the encapsulation and support of porcine embryo elongation in vitro. Secondly, alginate hydrogel was investigated as a 3-D matrix for the establishment of an in vitro growth plate model. Physical damage or congenital disorders that disrupt growth plate cartilage result in skeletal abnormalities that are often associated with long-term intensive healthcare needs due to impact on the joints, central nervous system, and ocular system. Studying the generation of growth plate architecture in vitro is critical for understanding mechanisms that regulate normal development of growth plate cartilage and how these mechanisms are altered in abnormal growth plates, in addition to enhancing tissue engineering strategies. Therefore, the second objective of this thesis was to determine the extracellular factors required to induce native growth plate structure and function within 3-D alginate hydrogels. Overall, in addition to advancing the field of developmental biology, the physiological knowledge that have been obtained within the usage of the mentioned vitro models as a study methodology that can be used to develop fertility and pregnancy outcomes as well as tissue engineering and cell-based therapies for the treatment of degenerative diseases.

\section{Tissue Engineering}

The use of autologous or allogeneic grafts in traditional transplantation surgeries has serious limitations, including a lack of available donor tissues and severe immune responses, respectively [1]. Tissue engineering is a relatively new field that combines engineering with the life sciences in order to develop functional tissue substitutes, and has the potential to revolutionize medicine by providing optimal replacement tissues for those damaged due to injury or disease [39]. Advantages of tissue engineering include the use of autologous or allogeneic cells to overcome the limitation of donor tissue availability, as well as the ability to directly control in vitro culture conditions to model those that occur in vivo [40]. The basic principle of tissue engineering involves three main components [41]. First, living cells are needed in order to produce the desired tissue. The cells are often derived from donor tissue or from stem or progenitor cells [39, 42]. Secondly, a 3-D scaffold is needed to provide structural support for the growing tissue and maintenance of cell-to-cell communication. These scaffolds often mimic the in vivo environment of the tissue by setting appropriate mechanical properties and chemical signals. Tissue engineering scaffolds can be made of synthetic materials, such as the polyglycolic or polylactic family of polymers, or they can be made of natural materials, such as collagen, alginate, or chitosan [43]. The final essential component of tissue engineering is the inclusion of bioactive signals, as they are used to establish cell-scaffold interactions and provide the necessary chemical stimuli to promote cell growth and differentiation [45]. Taken together, these three components of tissue 
engineering can act synergistically to develop functional tissue substitutes for the replacement of diseased or damaged tissue.

\section{Alginte hydrogel in Biomedical applications}

The main functions of alginate in the field of pharmaceutics is relatively favorable, it can act as several kinds of agents like thickening, stabilizing in addition of being gel forming, Alginate reveals a critical function in the drug products released control. The most common forms of alginate used are the oral ones used in the pharmaceutical applications, However the manipulation of the hydrogels of alginate regarding tissue localization has been growing. Here, in this paper we summarize the modern prognosis regarding controlled drug delivery within the usage of alginate in addition to the substances derived from it ..

Gels of alginate is highly promoted for the presenting of a numerous amount of drugs having low molecular value, amongst, it is considered to be useful for primary or secondary interactive bond within the required drug and thus alginate can be utilized to control the kinetic properties regarding the drug release. Alginate gels are considered to be identically nano-porous (pore size is approximately $5 \mathrm{~nm}$ ) [46], conducting a fast small molecules decomposition via the gel. such as, flurbiprofen release from the cross-linkage between the ions, portion ally, the formation of the oxidized alginate can be achieved in one and half hour. But, the beads incorporation has been manifested from an incompletely oxidized alginate within the existence of adipic acid dihydrazide as well as the calcium ions (combination of ionic and covalent cross-linkage ionic ally and covalently) leading to a sufficient release because of the relatively large number of cross-links and the obtained minimized edema [47]. Both the delivery of the antineoplastic agent that are performed locally in addition to the controlled can been accomplished via the gels of the incompletely oxidized alginate. Various drugs have the function of being loaded to the gels of based alginate for alternative means of presenting, For the reason that the drug chemical composition and their incorporation mode might influence the released kinetics. such as , methotrexate ( considered as a non-interactive in correlation to alginate) showed a fast diffused release, on the other hand doxorubicin, is highly liked with alginate, has gone to the process of release through the hydrolysis of the cross-linked chemicals. Mitoxantrone, is highly connected with alginate, can be only released when the gel dissociation is performed [48]. Amphiphilic gel beads are also utilized for the means of the modulation the of hydrophobic drugs release. Alginate that has been grafted via the poly $\varepsilon$-caprolactone has gone with calcium ions undergoing cross-linkage to control the obtaining of theophylline, a model drug have insufficient water solubility function. The total length of the chains of hydrophobic PCL chains can control the edematous structure of the gel beads, and the PCL revealed the theophylline process of release. The release of the drug can be achieved within the duration of two hours alginate- $g$-PCL/Ca2 + beads profile , and in only an hour regarding alginate/Ca2+ beads [49]. The theophylline release can be accomplished by using carbon nanotube (CNT)incorporated alginate microspheres. The proper loading of CNT improves the gels stability mechanically, lacking any structural impact of the microspheres structures showing low rate of cytotoxicity, with a potential application indicator to deliver a carrier for the colon and intestine [50].

Alginate is broadly extracted in several applications of drug delivery in correlation with chitosan, that acts as the ionic complexes combining form. Chitosan is known to be a chitin derivative product, the next highly polymer showing abundant characters most abundant natural polymer globally having the criterion of being duplicated $(1,4)$ linked $\beta$-D-glucosamine, in co-ordination with a calculated ph value $(6.5)$. Normally, commercial products include $20 \% \mathrm{~N}$-acetyl- $\beta$-D-glucosamine in addition to $80 \% \beta$-D-glucosamine [51]. Chitosan is considered to a polymer that acts catatonically and has been broadly utilized in tmany fields regarding of food, ,both pharmaceutical and biomedical applications as well as cosmetics [52], For the reason of being highly biocompatible and various positive characteristics. The systems of alginate and chitosan Multi-particulate with the inclusion of triamcinolone have been manifested via a compound gelation method of coacervation ionotropic for the means of colonic drug presentation. An increased level of edema and a quick delivery of the drug release were easily obtained from the particulate systems in a enteric environment that has been simulated ( with a $\mathrm{pH}$ value of 7.5), in comparison to a the gastric simulated environment (with a pH value of 1.2) [53]. The beads of Magnetic alginate-chitosan can be added within albendazole (ABZ) and performed for getting a non-active targeting towards GIT by the application of capture mechanisms physically (such as, magnetic field, $\mathrm{pH}$,etc). The beads revealed a specific pH-dependent edema criteria and a prolonged ABZ release [54]. The applied Chitosan alginate micro-particles including the required trans retinoic acid (ATRA) have obtained to develop the achieved release of ATRA that has been accomplished into the skin in addition to the dermal localization [55]. Metronidazole is also known to be in co-ordinance with chitosan that is treated by the beads of alginate via an ionotropic gelation way, it was clarified that the beads show a high degree of efficiency Helicobacter pylori undergoing the process of eradication when it is applied into mice orally [56]. Gels of alginate is performed to obtain a matrix though which the released depots of minor drugs can be easily interacted; The loaded chitosan/poly $(\gamma$-glutamic acid) nanoparticlesAmoxicillin are involved with the hydrogels alginate/Ca2+ in order to improve the H. pylori infection way of treatment. The outer surface of alginate gel 
layer is kept in the gastric environmentnanoparticles that have been loaded withamoxicillin, improving the interacting activity of the amoxicillin within the spaces located in the extra-cellular region, that is considered to be the site of $H$. pylori infection [57].

\section{D Cell culture in alginate hydrogel}

Gels of alginate have been highly used for the mammalian cell culture model system regarding most of the biomedical researches. The mentioned gels have the ability of acting in both 2-D and the physiologically high relevant 3-D systems of cultures. The reason that alginate doesn't have mammalian receptors of cells, in addition to the high rate of combination with the low adsorbed proteins regarding alginate gels permits these substances to interact in several methods as a proper space slate, upon within an increased quantitative and specific processes for the adhesion of the cells can be easily performed (as an example, synthetic peptides couple which is responsible for the adhesion of the cellular receptors).Moreover, the ordinary results did not focus on the vitro researches that undergo the process of translation in vivo, For the reason of being biocompatible and the ease alginate introduction throughout the body.

Gels of alginate undergoing modification by RGD are highly manipulated in vitro culture of the cell derivatives. The existence of RGD peptides in the gels of alginate prohibits a regular phenotype of interacting myoblasts over going interactions [58],osteoblasts, chondrocytes [ [59, 60], [61], follicle of the ovary [62], in addition to the stromal cells of the bone marrow [63-64].such as, the proliferation as well as adhesion of the cultured myoblasts on the gels of alginate were highly improved within conjugation of RGD peptides chemical products to the backbone profile of the alginate, in correlation to the gels of alginate that did not undergo modification(Fig. 13) [64]. Moreover, the amount of the adherent gelatinous cells, and the rate of growth , are significantly showing high rates of dependency regarding the gels RGD density bulk. The spacer-arm optimum amount of length within the peptide of the RGD and the sequence of alginate is a major regulating parameter of the responses of cells. The growth in addition to the adhesion of the ordinary fibroblasts of humans that reveal cultural procedure on the gels of alginate undergoing modification with a peptide chain of (glycine)n-arginineglycine-aspartic acid-serine-proline (GnRGDSP) that was highly affected by the spacer arm length measures , in contrary to the identical overall compositions of the gels peptides (Fig. 14). Minimally 4 units of glycines acting as a spacer arm prohibited linkage to the receptors of the cells, within the usage of twelve glycine units leading to non-enhancement in adhesion of the cells as well as the growth [ㄷ]. The RGD peptides amount for each chain of alginate, and the vacancy with the RGD peptides clusters, specifically of the total RGD ligands density, highly influence the cells rebound to the gels of alginate with RGD-modification [66, 67], probably these factors can impact the integrin receptors clusters [68]. However, the availability of the RGD ligands identically improves the differentiation and the adhesion of cells, chondrogenic gene expression in addition to the BMSCs accumulated matrix can undergo encapsulation in RGD- gels of alginate (3-D) that prevented with an high density of the RGD in vitro [69], Nowadays, gels of alginate have been expressed in a microfluidic apparatus via the release of the light-triggered caged calcium within the usage of DM-nitrophen ${ }^{\mathrm{TM}}$ complexes, and can be also utilized as a three-dimensional substrate of the cell culture. Prosteoblasts (MC3T3-E1) and the umbilical vein of the human endothelial cells were gonr through culture in the microfluidic apparatus by the manipulation of the photo-patterning of hydrogels derived from alginate, and this way lead to a valuable way for three-dimensional culture microenvironments integration with the microfluidic processes[70].

The peptide adhesion of the cell affinity of the receptors of the cells besides plays an important role in the response of the ,as was clarified in previous researches depending on a relatively high affinity of the cyclicpeptide RGD. The gels of the alginate delivering the cyclic peptide of RGD(glycine4-cystine-arginine-glycineaspartate-serine-proline-cystine; G4CRGDSPC) increased the ability of osteogens to be differentiated via stem cell (the stromal cells of the human being and the stromal cell line of the mousa bone marrow) more effective than that of the gels linear RGD peptides modified cells [70]. Cyclic peptide-RGD show high level of resistance towards the process of proteolysis [72], as well as an efficient binding ability in addition to selectivity than those regarding the linear-peptide RGD. [73-74]. The process of alginate synthesis extracts delivering an intimate cyclic-peptide RGD peptides with a high capability of controlling the differentiation of the stem cells and might increase the regeneration of the tissues via diminishing the intake of the exogenous factors that have the ability of being soluble.

Most of the researches that have been done recently depend on the usage of the gels of alginate as being three-dimensional cell culture substrates have resulted a major point in both cancer biology as well as the stem Mesenchymal stem cells have been conducted in order to be controllable with the RGD gels of the alginate elastic modulus for the purpose of encapsulation. For the reason that differentiation process break down both fat and bone ways of path it was carried out at various amounts of gel stiffness showing a proper contrast to two-dimensional culture systems manifested in the prior works done on the mechano-transduction, the ease of the stem cell to be controlled was showing a direct correlation with the adhesive bonds number that are obtained within the cells and the gels, in addition to the altered cell receptors that have been manipulated to 
enhance the adhesion the peptide of the RGD in 3-D opposes 2-D cuture systems. Reorganization of the active cells are then accomplished on the nano-scale of the ligands of the adhesion and extracted from the gels [75]. Moreover,The gels of the alginate could be utilized to inspect the ability of the three-dimensional culture microenvironment in impacting signaling of the cancer cells as well as the vascularization of the tumors. The engaging of Integrin via a three-dimensional micro-environment of the tumor the gels of the alginate(RGD) undergo encapsulation \} highly affect the signal of the cancer cells to attack the blood vessels, Therefore, this applied study might discover a recent anti-angiogenic cancer treatment therapies [76]. A highly weak point for most of the 3-D cell culture systems is the lack of the ease gaining quantifying of the cell matrix interactions as well as for the analysis. Even though, the enhancement of many FRET ways has achieved a new non predicted ability of the quantitative probe with co-relation of decision-making and the adhesion of the cells. In a singleFRET process, cell membranes are previously undergo staining within the usage of florescent molecules(known as the acceptor), and non-identical fluorophore (known as the donor) can be easily interacted to the peptides of the cell adhesion peptides and be alternated to the sequences of the polymer. (Fig. 3) [77]. The previously mentioned FRET way prohibits the ease of quantification of the cell receptor-ligand cross linkage and an identical FRET method promotes knowledge on the process of rearrangements of the mediated cells, at the size of nanometer scale, of the ligands of the adhesion connected with the gels [78-79]. we figured out the relation between the quantity of the bonds of the ligand receptors and the behavior of the cells by myoblasts $(\mathrm{C} 2 \mathrm{C} 12)$ and pre-osteoblasts (MC3T3-E1) encapsulation in the gels of alginate delivering the peptides of the RGD peptides via applying a single FRET methodology [이. The interactions of the adhesive products can be clearly inspected, because of the continuous emission of the green fluorescein in the membrane of the cell was reduced while the red emission from the rhodamine located at the interface within the gels and the cells was enhanced after encapsulation of the cells inrhodamine-G4RGDASSKY gels of the alginate ,Because of FRET application. Both the differentiation in addition to the proliferation showed a great degree of being dependent on the quantity of the bonds relate to the ligand receptors and measured by the signaling of FRET signal. The mentioned analytical process could enhance cell behavior predictability, partially in the three- dimensional culture, and to fabricate a valuable three-dimensional culture of the cell derivatives for further kinds of applications.

\section{Cell Culture}

Many studies have been done regarding the 3D cell culture adaptation for immobilization of the cell. a specific system cannot be applicable for other kinds of laboratory experiments and types of the cells, However ,It is obvious here that alginate permits an efficient tool system for optimization and fabrication. In the comparison between several methods, we have to put into consideration the evaluation and the formation of the multicellular spheroids. It is correlated with that fact that spheroids are obtained in the form of monoclonal or polyclonal originally. The monoclonal origin the spheroids are conducted through a uni-proliferation of the cell to locate cells in the most systems of hydrogels while polyclonal ones obtained from the process of cell population aggregation and can be cited during the usage of the plates of low attachment and hanging drop techniques.

Strategies for scaffolds knowledge as a correspondent to culture of the cell on two-dimensional plastics involving fibers, membranes, beads, foams as well as several types and morphologies of hydrogels [81]. The application of the two-dimensional cell culture into several scaffolds kinds improve the positive outcomes of the mono-layers than that for the plastics, in addition to a profound knowledge regarding the responses of the cells towards the stiffness function of the matrix and signaling factors of the interacted cells can be easily approached from these kind of experiments [82-83]. Four different strategies of hydrogels of the alginate are available in this part involving beads, postponed systems of gelation, macroporous scaffolds as well as the ptinted3D scaffolds. Other techniques investigating the 3D culture of the cell in the scaffolds of alginate are considered to be a kind of alginate scaffolds that is known ashoneycomb showing aligned pore structure for the means of vascularization enhancement [84], The magnetic responsive impregnation of the scaffolds nanoparticles can helps to stimulate the cells and initiate a chain of organized endothelial cells within a capillary-like characters [85], and scaffolds alginate together with hydroxyapatite that is nucleated and could be controlled conducting a composite scaffold with a high rate of prognosis for the engineering of the bone tissues [86-87].

Scaffolds of alginate for three-dimensional culture of the cell could be easily applied for a broad number of cell types. beside the interaction of cells that can be obtained with the involving to hydrogel through peptide-coupled alginates and that was discussed in Section 2.3.1,In order to get a proper control on the gels elasticity,alginate concentration optimization showed be highly controlled, the alginate kind and the crosslinkage strategy that will be chosen ( whether ionic or covalent) beside the density of the cross-linkage, hydrogels of the alginate could be fabricated to contrast the elastic function of most tissue kinds. (Figure 5) and could be applied for the means of stem cell differentiation control [88-89]. Huebsch et al. have revealed that formation of the bond within the mammalian mesenchymal stem cells (mMSCs) and the peptide of RGD have 
been highly correlated with the density of the existent peptides (7.5-150 $\mu \mathrm{M}$ RGD concentration) and the rigidity of the matrix (2.5-110 $\mathrm{kPa})$ therefore, delivering the major roles of the mentioned two parameters [69].

\section{Beads}

The method of the cells immobilization, especially the islet cells of pancreas, in the matrices of calcium alginate was discovered by Lim and Sun at the late 1970s [90]. By encapsulation of the gels of the alginate within polycations identical to poly-L-lysine, poly-L-ornithine, or chitosan, the strength of the coated surface coating in addition to the ability of controlling the porosity of the capsule (Figure 2) [91].

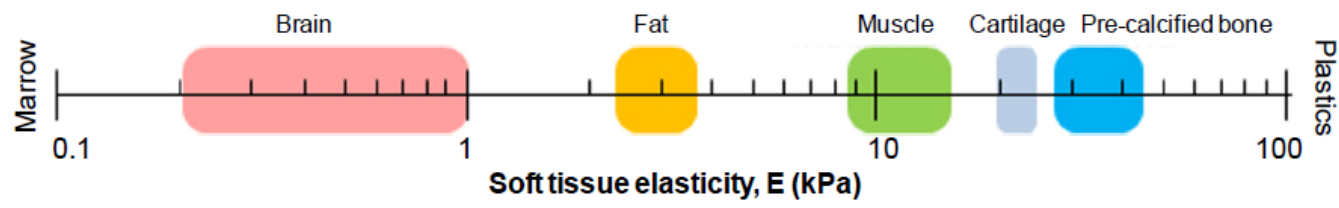

Figure 2. Elasticity scale of soft tissues. Adapted from reference [91]. Reprinted with permission from AAAS.

A major criterion of alginates is the low inherent cell adhesion and interaction of the cells. This can be a reason for cell encapsulation applications improvement, however it could be a weak point regarding tissue engineering applications. However, alginate could be changed via the peptide application to the cell attachment or another molecules that are biologically active The process of encapsulation of hydrogel of the alginate is a quick non-toxic way for gaining immobilization for both cells and macro-molecules. Obtaining artificial organs via cells or tissue encapsulation process is considered to be a major point study for the means of several diseases treatment like Parkinson's disease, failure of the hepatic functions, hypocalcemia in addition to the chronic prolonged pain, probably the most famous is artificial pancreas that is used for diabetes treatment (pancreatic islets encapsulation).

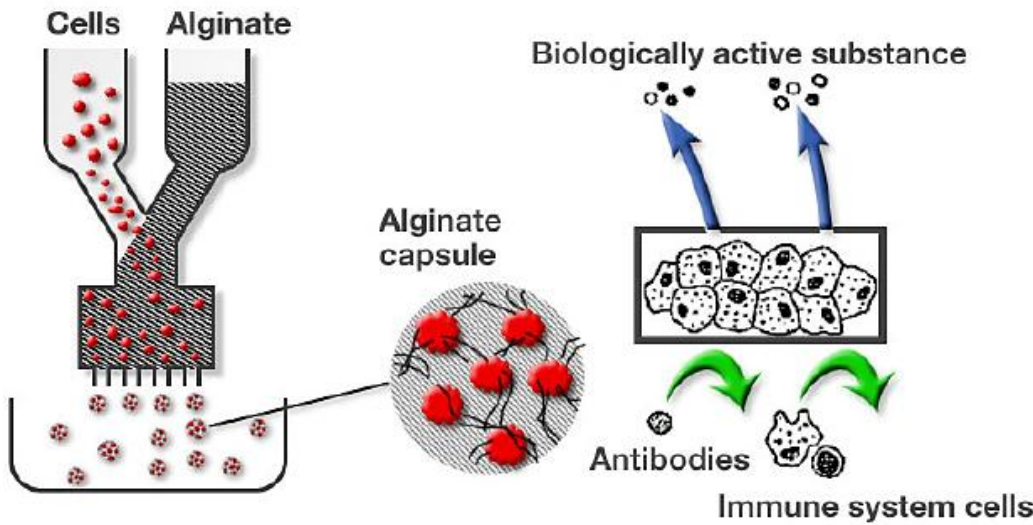

Figure 3. Encapsulation of cells with alginate. (From FMC internal archive.)

Almost all of the ways methods regarding tissues and cells encapsulation in the gels of alginate mainly include two major mechanisms. The initiative mechanism deals with the inner phase fabrication that the solution of the alginate having the biological materials incubated into minute drops. For the second mechanism, all the drops undergo solidification with either gelling or by the membrane formation at the superficial layer of the droplet.

The average size of the bead is highly considerable for both the alginate gel beads and capsules during the application of the biomedical products . The intimate size approach should highly compromised. The bead needs to be big enough for the ease of the biological material inclusion. A relatively larger ones can be simply handled in case of washing process or another treatments. In several applications of including cells, they have to be harmonically distributed with the inner matrix of the capsule. Thus, beads undergoing generation with the a proper mean size and reasonable size distribution must be measured. The beads size can be easily controlled through regulation of droplet formation.

The size of the droplet size depends on various points: the overall size of the material undergo immobilization and/or encapsulation (islets of pancreas as an example for the mono-cells or the cell aggregates) the strategy is proposed for the droplets generation (as an example, the usage of syringe and pipette, co-axial flow of the air, electrostatic generation, jet-cutter), the viscous ability of the solution of of the alginate, 
and the rangle of the flow of alginate. Therefore, when talking about the biomedical applications, regulation of the size of the droplet is considered to deliver a gelled bead with a measured a diameter of less than 200-1000 $\mu \mathrm{m}$. For each unit volume, a relatively small beads present a broader surface area for transplantation, a calculated ratio that appeals in improving the tissue survival because of the proper nutritional as well as the oxygen supply. Several methods can be utilized for the droplets formation, as mentioned in a work done by Dulieu et al. [92]. Involving:

- Extrusion by the usage of a needle: Beads could be obtained by dispensing the solution of the alginate from a syringe within a proper needle diameter straightly to bath gelling . despite, this technique does not need any using of instruments, the distribution size of the beads undergoing production cannot be easily controlled.

- Coaxial flow for liquid and air: The air jet coaxial system is an easy method of relatively small beads generation (around $400 \mu \mathrm{m}$ ), even though the distribution size shows a slight enlargement in comparison to the electro-static system. In this system, a coaxial stream of the air is manipulated to get out the droplets from the tip of the needle to the gelling bath Figure 4.

- Electrostatic potential: The electrostatic potential is considered to be useful in pulling out the droplets from the tip of the needle to the gelling bath. The major influence on the formation of the droplet through the electrostatic potential can directly enhance the charged molecules to the superficial layer of the droplet to overcome the tension of the surface. Within the usage of this kind of instrument, The beads size lower than 200 $\mu \mathrm{m}$ and with a small size distribution might undergo generation. The targeted bead size is accomplished easily by the instrument voltage adjustment (electrostatic potential). The major line of smaller beads fabrication using electrostatic potential bead generators is illustratedinFigure 4.
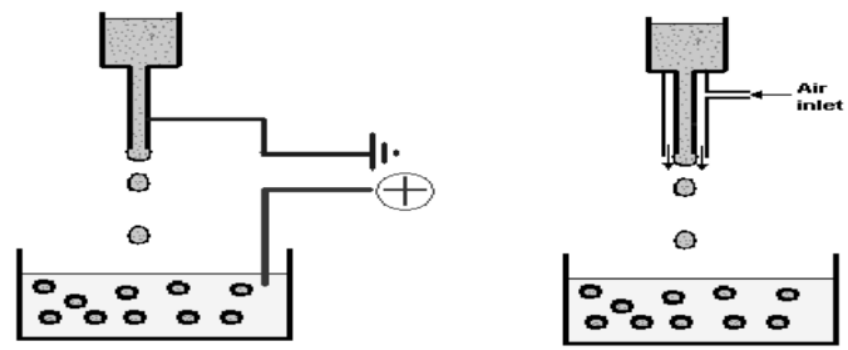

Figure 4. Principle of electrostatic (left) and coaxial air flow (right) bead generators [80].

- Vibrating capillary jet breakage: A vibrating nozzle has the ability to generate the drops from a vessel showing a high value of pressure.

- Rotating capillary jet breakage: The generation of the bead is obtained via the removal a rigid jet of fluid extrusion of a nozzle by the usage of cutting device having rotational ability. The fluid is then segmented into cylindrical parts then forming the beads because of surface tension ability when passing the gelling bath.

Figure 7. The concept of electrostatic (left) and coaxial flow of air (right) generation of the beads [93]. The process of Encapsulation of the vital cells, an immobilized cell form immobilization, is an applied technique for artificial organs production and the therapy of cells constructs. The cells can be integrated through alginate( with adjusted osmolality )following by dripping of the solution of the alginate positive cells into calcium chloride bath (Figure 6). For the reason that the ionic cross-linkage reaction is intermittent, the cells are intervened inside in the hydrogel bead of the alginate. The of the beam of the alginate to be porous like oxygen and nutrient substances can be easily diffused into the gel, on the other hand, cell products, like proteins, are diffuse outside the gel. The hydrogel is considered to be a porous barrier for antibodies and immune cells as an example macrophages., it can go through the process of implantation of the hydrogel of the alginate "biofactory" to both humans and animals where the implant can be revealed as a continuous production system such as insulin for example. Implantation researchers into patients suffering diabetes and animals [94-95] have carried out long-term of functions .

Several examples of cells undergoing encapsulation are illustrated in Figure 5. 


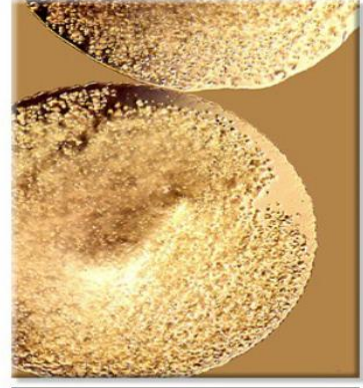

Mouse 3T3

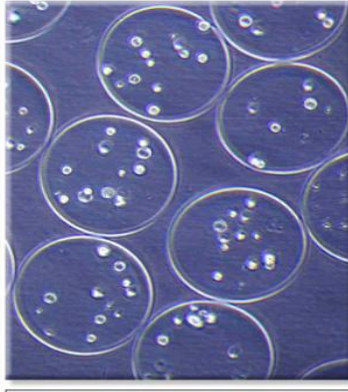

HEK 293

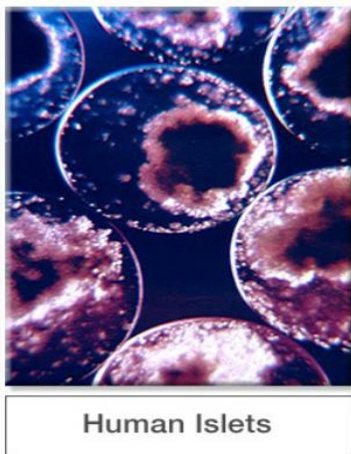

Human Islets

Figure 5. encapsulated cells in alginate. (From FMC internal archive.)

The mentioned photomicrographs are not showing the same magnification level. The left panel indicates the genetically engineered murine 3T3 cells undergoing the process of encapsulation. Encapsulated Human fetal Kidney (HEK) 293 cells are illustrated in the core panel. The islets of pancreas having encapsulation in the gel beads of the alginate are specified in the right panel. Cells that are capable of the antiangiogenic protein endostatin production have been undergoing encapsulation in the extra pure alginate followed by implantation into the brains of dogs treated for a diagnostic brain cancer [84-86]. Various cell kinds have performed immobilization in alginate as an example adipose-derived stem cells [95-96], mesenchymal stem cells [97], and chondrocytes[97-98]. Disease in addition to diabetes are represented on the web pages of vital Cell strategies [98].

\section{Conclusions}

Culturing cells and tissue engineering in alginat Hydrogyl will be the preferred way to investigate cell growth in tissue, mechanisms of cell differentiation and still there is various formulation are still under realization for constructing used buy alginat hydrogyl and 3D alginat Hydrogyl in filde as diverse as tissue engineering and drug discovery this should not be detrimental to the use of $3 \mathrm{D}$ cell or tissue system but rather an opportunity to improve and customize assay system for cellular structure.

\section{Acknowledgment}

This work was supported by National Natural Science Foundation of China (21574050, 31270150, 51603079), China Postdoctoral Science Foundation (2016M602291), Fundamental Research Funds for the Central Universities, Open Research Fund of State Key Laboratory of Polymer Physics and Chemistry, Changchun Institute of Applied Chemistry, Chinese Academy of Science.

\section{References}

[1]. Enas M. Ahmed, Fatma S. Aggor, Ahmed M. Awad, Ahmed T. El-Are An innovative method for preparation of nanometal hydroxide superabsorbent hydrogel Carbohydr Polym, 91 (2013), pp. 693-69

[2]. Huebsch N, Mooney DJ. Inspiration and application in the evolution of biomaterials. Nature. 2009; 462:426-432. [PubMed: 19940912]

[3]. Ratner BD, Bryant SJ. Biomaterials: where we have been and where we are going? Ann Rev Biomed Eng. 2004; 6:41-75. [PubMed: 15255762]

[4]. Williams DF. On the nature of biomaterials. Biomaterials. 2009; 30:5897-5909. [PubMed: 19651435]

[5]. Draget, K.I., et al., Swelling and partial solubilization of alginic acid gel beads in acidic buffer. Carbohydrate Polymers, 1996. 29(3): p. 209-215.5. Langer R, Vacanti JP. Tissue engineering. Science. 1993;260:920-926. [PubMed]Lewis

[6]. scaffold produced by electrospinning of their aqueous solution for tissue engineering applications. Advances in Material Design for Regenerative Medicine, Drug Delivery and Targeting/Imaging, 2009. 1140: p. 131- 136

[7]. Andersen, T. Alginate Foams as Biomaterials. Ph.D. Thesis, Norwegian University of Science and Technology, Trondheim, Norway, 2013

[8]. Atkins, E.D.; Mackie, W.; Parker, K.D.; Smolko, E.E. Crystalline Structures of Poly-D- Mannuronic and Poly-L-Guluronic Acid. J. Polymer Sci. B Polymer Lett. 1971, 9, 311-316.

[9]. Atkins, E.D.; Mackie, W.; Smolko, E.E. Crystalline Structures of Alginic Acids. Nature 1970, 225, 626-628. Haug, A. Composition and properties of alginates. Ph.D. Thesis, University of Trondheim, Trondheim, Norway, 1964.

[10]. Landa, N., et al., Effect of injectable alginate implant on cardiac remodeling and function after recent and old infarcts in rat. Circulation, 2008. 117(11): p. 1388-96.

[11]. Cohen, D.L., et al., Direct freeform fabrication of seeded hydrogels in arbitrary geometries. Tissue Eng, 2006. 12(5): p. 1325-35.

[12]. Leor, J., et al., Intracoronary injection of in situ forming alginate hydrogel reverses left ventricular remodeling after myocardial infarction in Swine. J Am Coll Cardiol, 2009. 54(11): p. 1014-23.

[13]. Lee KY, Bouhadir KH, Mooney DJ. Degradation behavior of covalently cross-inked poly(aldehyde guluronate) hydrogels. Macromolecules. 2000;33:97-101.

[14]. Kong HJ, Kaigler D, Kim K, Mooney DJ. Controlling rigidity and degradation of alginate hydrogels via molecular weight distribution. Biomacromolecules. 2004;5:1720-1727. [PubMed] 
[15]. Kong HJ, Alsberg E, Kaigler D, Lee KY, Mooney DJ. Controlling degradation of hydrogels via the size of cross-linked junctions. Adv Mater. 2004;16:1917-1921. [PMC free article] [PubMed]

[16]. Boontheekul T, Kong HJ, Mooney DJ. Controlling alginate gel degradation utilizing partial oxidation and bimodal molecular weight distribution. Biomaterials. 2005;26:2455-2465. [PubMed]

[17]. Maiti S, Singha K, Ray S, Dey P, Sa B. Adipic acid dihydrazide treated partially oxidized alginate beads for sustained oral delivery of flurbiprofen. Pharm Develop Technol. 2009;14:461-470. [PubMed]

[18]. Bouhadir KH, Alsberg E, Mooney DJ. Hydrogels for combination delivery of antineoplastic agents. Biomaterials. 2001;22:26252633. [PubMed]

[19]. Dixit R, Boelsterli UA: Healthy animals and animal models of human disease(s) in safety assessment of human pharmaceuticals, including therapeutic antibodies. Drug Discov Today 2007, 12(7-8):336-342. Smitz JE, Cortvrindt RG: The earliest stages of folliculogenesis in vitro. Reproduction 2002, 123(2):185-202. Smalley KS, Lioni M, Herlyn M: Life isn't flat: taking cancer biology to the next dimension. In Vitro Cell Dev Biol Anim 2006, 42(8-9):242-247.

[20]. Gilbert SF: Ecological developmental biology: developmental biology meets the real world. Dev Biol 2001, 233(1):1-12. Machado GM, Caixeta ES, Lucci CM, Rumpf R, Franco MM, Dode MA: Post- hatching development of bovine embryos in vitro: the effects of tunnel preparation and gender. Zygote 2012, 20(2):123-134. Brandao DO, Maddox-Hyttel P, Lovendahl P, Rumpf R, Stringfellow D, Callesen H: Post hatching development: a novel system for extended in vitro culture of bovine embryos. Biol Reprod 2004, 71(6):2048-2055. Sargus-Patino CN, Wright EC, Plautz SA, Miles JR, Vallet JL, Pannier AK: In Vitro Development of Pre-implantation Porcine Embryos using Alginate Hydrogels as a Three-Dimensional Extracellular Matrix. Reprod Fertil Dev 2013.

[21]. Krentz KJ, Nebel RL, Canseco RS, Mcgilliard ML: Invitro and Invivo Development of Mouse Morulae Encapsulated in 2-Percent Sodium Alginate or 0.1-Percent Poly-L-Lysine. Theriogenology 1993, 39(3):655-667. Bursac N, Papadaki M, Cohen RJ, Schoen FJ, Eisenberg SR, Carrier R, Vunjak- Novakovic G, Freed LE: Cardiac muscle tissue engineering: toward an in vitro model for electrophysiological studies. The American journal of physiology 1999, 277(2 Pt 2):H433-444.

[22]. Groeber F, Holeiter M, Hampel M, Hinderer S, Schenke-Layland K: Skin tissue engineering--in vivo and in vitro applications. Adv Drug Deliv Rev 2011, 63(4- 5):352-366.

[23]. Shin CS, Kwak B, Han B, Park K: Development of an in vitro 3D tumor model to study therapeutic efficiency of an anticancer drug. Mol Pharm 2013, 10(6):2167- 2175.

[24]. Talukdar S, Mandal M, Hutmacher DW, Russell PJ, Soekmadji C, Kundu SC: Engineered silk fibroin protein 3D matrices for in vitro tumor model. Biomaterials 2011, 32(8):2149-2159.

[25]. Andersen T, Strand, B., Formo, K., Alsberg, E., Christensen, B.: Alginates as biomaterials in tissue engineering. Journal of Carbohydrate Chemistry 2012, 37:227-258

[26]. Aydelotte MB, Thonar EJ, Mollenhauer J, Flechtenmacher J: Culture of chondrocytes in alginate gel: variations in conditions of gelation influence the structure of the alginate gel, and the arrangement and morphology of proliferating chondrocytes. In Vitro Cell Dev Biol Anim 1998, 34(2):123-130.

[27]. Gombotz WR, Wee SF: Protein release from alginate matrices. Adv Drug Deliv Rev 1998, 31(3):267-285. Rowley JA, Madlambayan G, Mooney DJ: Alginate hydrogels as synthetic extracellular matrix materials. Biomaterials 1999, 20(1):45-53

[28]. West ER, Xu M, Woodruff TK, Shea LD: Physical properties of alginate hydrogels and their effects on in vitro follicle development. Biomaterials 2007, 28(30):4439-4448.

[29]. Alshamkhani A, Duncan R: Radioiodination of Alginate Via Covalently-Bound Tyrosinamide Allows Monitoring of Its Fate inVivo. J Bioact Compat Pol 1995, 10(1):4-13.

[30]. Kong HJ, Kaigler D, Kim K, Mooney DJ: Controlling rigidity and degradation of alginate hydrogels via molecular weight distribution. Biomacromolecules 2004, 5(5):1720-1727

[31]. Shoichet MS, Li RH, White ML, Winn SR: Stability of hydrogels used in cell encapsulation: An in vitro comparison of alginate and agarose. Biotechnol Bioeng 1996, 50(4):374-381. Wong TY, Preston LA, Schiller NL: ALGINATE LYASE: review of major sources and enzyme characteristics, structure-function analysis, biological roles, and applications. Annи Rev Microbiol 2000, 54:289-340

[32]. Lee KY, Mooney DJ: Alginate: properties and biomedical applications. Prog Polym Sci 2012, 37(1):106-126. Schoubben A, Blasi P, Giovagnoli S, Perioli L, Rossi C, Ricci M: Novel composite microparticles for protein stabilization and delivery. European journal of pharmaceutical sciences : official journal of the European Federation for Pharmaceutical Sciences 2009, 36(2-3):226-234.

[33]. Rasool BK, Fahmy SA: Development of coated beads for oral controlled delivery of cefaclor: In vitro evaluation. Acta Pharm 2013, 63(1):31-44

[34]. Martinez A, Muniz, E., Iglesias, I., Teijón, J.M., Blanco, M.D.: Enhanced preclinical efficacy oftamoxifen developed as alginatecysteine/disulfide bond reduced albumin nanoparticles. Int J Pharm 2012, 436:574-581. Alsberg E, Anderson KW, Albeiruti A, Rowley JA, Mooney DJ: Engineering growing tissues. Proc Natl Acad Sci U S A 2002, 99(19):12025-12030.

[35]. Ab-Rahim S, Selvaratnam L, Raghavendran HRB, Kamarul T: Chondrocyte- alginate constructs with or without TGF-beta 1 produces superior extracellular matrix expression than monolayer cultures. Mol Cell Biochem 2013, 376(1-2):11- 20.

[36]. Hill E, Boontheekul T, Mooney DJ: Designing scaffolds to enhance transplanted myoblast survival and migration. Tissue Eng 2006, 12(5):1295-1304.

[37]. Rowley JA, Mooney DJ: Alginate type and RGD density control myoblast phenotype. J Biomed Mater Res 2002, 60(2):217-223

[38]. Purcell EK, Singh A, Kipke DR: Alginate composition effects on a neural stem cell-seeded scaffold. Tissue Eng Part C Methods 2009, 15(4):541-550.

[39]. Candiello J, Singh SS, Task K, Kumta PN, Banerjee I: Early differentiation patterning of mouse embryonic stem cells in response to variations in alginate substrate stiffness. J Biol Eng 2013, 7(1):9. Elsheikh AS, Takahashi Y, Hishinuma M, Nour MS, Kanagawa H: Effect of encapsulation on development of mouse pronuclear stage embryos in vitro. Anim Reprod Sci 1997, 48(2-4):317-324. Subramanian B, Rudym D, Cannizzaro C, Perrone R, Zhou J, Kaplan DL: Tissue- engineered three-dimensional in vitro models for normal and diseased kidney. Tissue Eng Part A 2010, 16(9):2821-2831.

[40]. Xu M, Kreeger PK, Shea LD, Woodruff TK: Tissue-engineered follicles produce live, fertile offspring. Tissue Eng 2006, 12(10):2739-2746. 114

[41]. Kreeger PK, Deck JW, Woodruff TK, Shea LD: The in vitro regulation of ovarian follicle development using alginate-extracellular matrix gels. Biomaterials 2006, 27(5):714-723.

[42]. Xu M, West-Farrell ER, Stouffer RL, Shea LD, Woodruff TK, Zelinski MB: Encapsulated Three-Dimensional Culture Supports Development of Nonhuman Primate Secondary Follicles. Biol Reprod 2009, 81(3):587-594. Kedem A, Hourvitz A, Fisch B, Shachar M, Cohen S, Ben-Haroush A, Dor J, Freud E, Felz C, Abir R: Alginate scaffold for organ culture of cryopreserved-thawed human ovarian cortical follicles. J Assist Reprod Genet 2011, 28(9):761-769. 
[43]. King SM, Quartuccio S, Hilliard TS, Inoue K, Burdette JE: Alginate hydrogels for three-dimensional organ culture of ovaries and oviducts. Journal of visualized experiments : JoVE 2011(52).

[44]. Xu M, West E, Shea LD, Woodruff TK: Identification of a stage-specific permissive in vitro culture environment for follicle growth and oocyte development. Biol Reprod 2006, 75(6):916-923. Yamamoto M., James D., Li H., Butler J., Rafii S., Rabbany S. Generation of Stable Co-Cultures of Vascular Cells in a Honeycom Alginate Scaffold. Tissue Eng. Part A. 2010;16:299-308. doi: 10.1089/ten.tea.2009.0010. [PMC free article] [PubMed] [Cross Ref]

[45]. Sapir Y., Cohen S., Friedman G., Polyak B. The Promotion of In Vitro Vessel-like Organization of Endothelial Cells in Magnetically Responsive Alginate Scaffolds. Biomaterials. 2012;33:4100-4109. doi: 10.1016/j.biomaterials.2012.02.037. [PMC free article] [PubMed] [Cross Ref]

[46]. Suárez-González D., Barnhart K., Saito E., Vanderby R., Hollister S.J., Murphy W.L. Controlled nucleation of hydroxyapatite on alginate scaffolds for stem cell-based bone tissue engineering. J. Biomed. Mater. Res. A. 2010;95:222-234. doi: 10.1002/jbm.a.32833. [PMC free article] [PubMed] [Cross Ref]

[47]. Westhrin M., Xie M., Olderøy M.Ø., Sikorski P., Strand B.L., Standal T. (2015) Osteogenic Differentiation of Human Mesenchymal Stem Cells in Mineralized Alginate Matrices. PLoS One. 2015;10:e0120374. doi: 10.1371/journal.pone.0120374. [PMC free article] [PubMed] [Cross Ref]

[48]. Discher D.E., Mooney D.J., Zandstra P.W. Growth Factors, Matrices, and Forces Combine and Control Stem Cells. Science. 2009;324:1673-1677. doi: 10.1126/science.1171643. [PMC free article] [PubMed] [Cross Ref]

[49]. Banerjee A., Arha M., Choudhary S., Ashton R.S., Bhatia S.R., Schaffer D.V., Kane R.S. The Influence of Hydrogel Modulus on the Proliferation and Differentiation of Encapsulated Neural Stem Cells. Biomaterials. 2009;30:4695-4699. doi: 10.1016/j.biomaterials.2009.05.050. [PMC free article] [PubMed] [Cross Ref]

[50]. Engler A.J., Sen S., Sweeney H.L., Discher D.E. Matrix Elasticity Directs Stem Cell Lineage Specification. Cell. 2006;126:677689. doi: 10.1016/j.cell.2006.06.044. [PubMed] [Cross Ref]

[51]. Andersen T., Markussen C., Dornish M., Heier-Baardson H., Melvik J.E., Alsberg E., Christensen B.E. In Situ Gelation for Cell Immobilization and Culture in Alginate Foam Scaffolds. Tissue Eng. A. 2013;20:600-610. [PMC free article] [PubMed]

[52]. Skjåk-Bræk G., Espevik T. Application of Alginate Gels in Biotechnology and Biomedicine. Carbohydr. Eur. 1996;14:19-25.

[53]. Dulieu C., Poncelet D., Neufeld R.J. Encapsulation and Immobilization Techniques. In: Kühtreiber W.M., Lanza R.P., Chick W.L., editors. Cell Encapsulation Technology and Therapeutics. Birkhäuser; Boston, MA, USA: 1999.

[54]. Bead generators. 2014. [(accessed online $6 \quad$ February 2015)]. Available online: http://www.novamatrix.biz/Products/BeadGenerators.aspx, NovaMatrix.

[55]. Soon-Shiong P., Feldman E., Nelson R., Heintz R., Yao Q., Yao Z., Zheng T., Merideth N., Skjåk-Bræk G., Espevik T., Smidsrød O., Sandford P. Long-Term Reversal of Diabetes by the Injection of Immunoprotected Islets. Proc. Natl. Acad. Sci. USA. 1993;90:5843-5847. doi: 10.1073/pnas.90.12.5843. [PMC free article] [PubMed] [Cross Ref]

[56]. Calafiore R., Basta G., Luca G., Lemmi A., Montanucci M.P., Calabrese G., Racanicchi L., Mancuso F., Brunetti P. Microencapsulated Pancreatic Islet Allografts into Nonimmunosuppressed Patients With Type 1 Diabetes. Diabetes Care. 2006;29:137-138. doi: 10.2337/diacare.29.01.06.dc05-1270. [PubMed] [Cross Ref]

[57]. Tuch B.E., Keogh G.W., Williams L.J., Wu W., Foster J.L., Vaithilingam V., Philips R. Safety and Viability of Microencapsulated Human Islets Transplanted into Diabetic Humans. Diabetes Care. 2009;32:1887-1889. doi: 10.2337/dc09-0744. [PMC free article] [PubMed] [Cross Ref]

[58]. Bjerkvig R., Read T.-A., Vajkoczy P., Aebischer P., Pralong W., Platt S., Melvik J.E., Hagen A., Dornish M. Cell Therapy Using Encapsulated Cells Producing Endostatin. Acta Neurochir. Suppl. 2003;88:137-141. [PubMed]

[59]. Read T.-A., Sørensen D.R., Mahesparan R., Enger P.Ø., Timpl R., Olsen B.R., Hjelstuen M., Haraldseth O., Bjerkvig R. Local Endostatin Treatment of Gliomas Administered by Microcapsulated Producer Cells. Nat. Biotechnol. 2001;19:29-34. doi: 10.1038/83471. [PubMed] [Cross Ref]

[60]. Read T.-A., Farhadi M., Holtan S., Olsen B.R., Huzthy P., Bjerkvig R., Vajkoczy P. Intravital Microscopy reveals novel antivascular and tumour effects ef endostatin delivered locally by alginate encapsulated cells. Cancer Res. 2001;61:6830-6837. [PubMed]

[61]. Moyer H.R., Kinney R.C., Singh K.A., Williams J.K., Schwartz Z., Boyan B.D. Alginate microencapsulation technology for the percutaneous delivery of adipose-derived stem cells. Ann. Plast. Surg. 2010;65:497-503. doi: 10.1097/SAP.0b013e3181d37713. [PubMed] [Cross Ref]

[62]. Khosravizadeh Z., Razavi S., Bahramian H., Kazemi M. The beneficial effect of encapsulated human adipose-derived stem cells in alginate hydrogel on neural differentiation. J. Biomed. Mater. Res. B Appl. Biomater. 2014;102:749-755. doi: 10.1002/jbm.b.33055. [PubMed] [Cross Ref]

[63]. Olderøy M.Ø., Lilledahl M.B., Sandvold M., Melvik J.E., Reinholt F., Sikorski P., Brinchmann J.E. Biochemical and structural characterization of neocartilage formed by mesenchymal stem cells in alginate hydrogels. PLoS One. 2014;9:e91662. doi: 10.1371/journal.pone.0091662. [PMC free article] [PubMed] [Cross Ref]

[64]. Bidarra S.J., Barrias C.C., Barbosa M.A., Soares R., Granja P.L. Immobilization of human mesenchymal stem cells within RGDgrafted alginate microspheres and assessment of their angiogenic potential. Biomacromolecules. 2010;11:1956-1964. doi: 10.1021/bm100264a. [PubMed] [Cross Ref]

[65]. Bittencourt R.A. C., Pereira H.R., Felisbino S.L., Ferreira R.R., Guilherme G.R. B., Moroz A., Deffune E. Chondrocyte cultures in tridimensional scaffold: alginate hydrogel. Acta Ortop. Bras. 2009;17:242-246. doi: 10.1590/S1413-78522009000400011. [Cross Ref]

[66]. Lin Y.-J., Yen C.-N., Hu Y.-C., Liao C.-J., Chu I.-M. Chondrocytes culture in three-dimensional porous alginate scaffolds enhanced cell proliferation, matrix synthesis and gene expression. J. Biomed. Mater. Res. 2008;88A:23-33. [PubMed]

[67]. NTCELL® for Parkinson's disease. [(accessed on 20 March 2015)]. Available online: http://www.lctglobal.com/products/ntcell/about-parkinsons-disease, Living Cell Technologies.

[68]. DIABECELL® for type 1 diabetes. [(accessed on 20 March 2015)]. Available online: http://www.lctglobal.com/products/diabecell/about-type-1-diabetes, Living Cell Technologies.

[69]. Herlofsen S.R., Küchler A.M., Melvik J.E., Brinchmann J.E. Chondrogenic Differentiation of Human Bone Marrow-Derived Mesenchymal Stem Cells in Self-Gelling Alginate Discs Reveals Novel Chondrogenic Signature Gene Clusters. Tissue Eng. A. 2011;17:1003-1013. doi: 10.1089/ten.tea.2010.0499. [PMC free article] [PubMed] [Cross Ref]

[70]. Jang J., Seol Y.J., Kim H.J., Kundu J., Kim S.W., Cho D.W. Effects of alginate hydrogel cross-linking density on mechanical and biological behaviors for tissue engineering. J. Mech. Behav. Biomed. Mater. 2014;37:69-77. doi: 10.1016/j.jmbbm.2014.05.004. [PubMed] [Cross Ref] 
[71]. Alsberg E., Anderson K.W., Albeiruti A., Franceschi R.T., Mooney D.J. Cell-Interactive Alginate Hydrogels for Bone Tissue Engineering. J. Dent. Res. 2001;80:2025-2029. doi: 10.1177/00220345010800111501. [PubMed] [Cross Ref]

[72]. Atala A., Kim W., Paige K.T., Vacanti C.A., Retik A.B. Endoscopic Treatment of Vesicoureteral Reflux With a ChondrocyteAlginate Suspension. J. Urol. 1994;152:641-643. [PubMed]

[73]. Principle of self-gelling alginate. 2011. [(accessed on 30 January 2015)]. Available online: http://novamatrix.biz/Portals/novamatrix/Content/Docs/Technology/Injectable\%20alginate\%20self\%20gelling\%20technology-

060911.pdf, NovaMatrix.62. Boontheekul T, Kong HJ, Mooney DJ. Controlling alginate gel degradation utilizing partial oxidation and bimodal molecular weight distribution. Biomaterials. 2005;26:2455-2465. [PubMed]

[74]. Maiti S, Singha K, Ray S, Dey P, Sa B. Adipic acid dihydrazide treated partially oxidized alginate beads for sustained oral delivery of flurbiprofen. Pharm Develop Technol. 2009;14:461-470. [PubMed]

[75]. Bouhadir KH, Alsberg E, Mooney DJ. Hydrogels for combination delivery of antineoplastic agents. Biomaterials. 2001;22:26252633. [PubMed]

[76]. Colinet I, Dulong V, Mocanu G, Picton L, Le Cerf D. New amphiphilic and pH-sensitive hydrogel for controlled release of a model poorly water-soluble drug. Eur J Pharm Biopharm. 2009;73:345-350. [PubMed]

[77]. Zhang XL, Hui ZY, Wan DX, Huang HT, Huang J, Yuan H, Yu JH. Alginate microsphere filled with carbon nanotube as drug carrier. Int J Biol Macromol. 2010;47:389-395. [PubMed]

[78]. Sandford PA, Steinnes A. Biomedical application of high-purity chitosan. In: Shalaby SW, McCormick CL, Butler GB, editors. Water-soluble polymers: synthesis, solution properties, and applications. vol. 467. Washington DC: Am Chem Soc; 1991. pp. 430445.

[79]. Rinaudo M. Chitin and chitosan: properties and applications. Progr Polym Sci. 2006;31:603-632.

[80]. 69. Lucinda-Silva RM, Salgado HRN, Evangelista RC. Alginate-chitosan systems: in vitro controlled release of triamcinolone and in vivo gastrointestinal transit. Carbohydr Polym. 2010;81:260-268.

[81]. Wang FQ, Li P, Zhang JP, Wang AQ, Wei Q. A novel pH-sensitive magnetic alginate74 chitosan beads for albendazole delivery. Drug Dev Ind Pharm. 2010;36:867-877. [PubMed]

[82]. Lira AAM, Rossetti FC, Nanclares DMA, Neto AF, Bentley MVLB, Marchetti JM. Preparation and characterization of chitosantreated alginate microparticles incorporating all-trans retinoic acid. J Microencapsulation. 2009;26:243-250. [PubMed]

[83]. Ishak RAH, Awad GAS, Mortada ND, Nour SAK. Preparation, in vitro and in vivo evaluation of stomach-specific metronidazoleloaded alginate beads as local anti-Helicobacter pylori therapy. J Controlled Release. 2007;119:207-214. [PubMed]

[84]. Chang CH, Lin YH, Yeh CL, Chen YC, Chiou SF, Hsu YM, Chen YS, Wang CC. Nanoparticles incorporated in pH-sensitive hydrogels as amoxicillin delivery for eradication of Helicobacter pylori. Biomacromolecules. 2010;11:133-142. [PubMed] 